\title{
Difficulties and Countermeasures of Cultivating Rule of Law Thinking of Leading Cadres
}

\author{
Zhang Kuohai \\ School of Humanities, Economics and Law \\ Northwestern Polytechnical University \\ Xi'an, China
}

\begin{abstract}
Leading cadre is the important force during the construction of a country under the rule of law. We need to catch the "key minority" when comprehensively ruling the country by law. The focus of leading cadres is to cultivate their rule of law thinking. At present, the cultivation of rule of law thinking of leading cadres is restricted by difficulties such as traditional "official-oriented" thinking, political-legal thinking and quality of leading cadres. The countermeasures such as establishing the normal and institutional mechanism of law-related education for leading cadres, stimulating their internal motivation of rule of law thinking and strengthening awareness of civil rights to develop rule of law thinking of leading cadres become the inevitable choice.
\end{abstract}

Keywords-leading cadres, rule of law thinking, cultivation, difficulties, countermeasures

\section{DiFFICULTIES IN CULTIVATING RULE OF LAW THINKING OF LEADING CADRES}

As a way of thinking, rule of law thinking is not inborn but developed during long-term practice. It is subject to the special national and social conditions of China. Cultivating rule of law thinking of leading cadres cannot be completed overnight but will go through a long process and face a variety of difficulties and challenges.

\section{A. Traditional "official-oriented" thinking will counter the cultivation of rule of law thinking of leading cadres}

At present, the definition of rule of law thinking has not reached a consensus yet in academia. Scholars have interpreted the connotation of rule of law thinking from different perspectives. From the perspective of thinking process of rule of law, Professor Jiang Ming'an argues that rule of law thinking is "an ideological activity and process that executives apply legal norms, legal aids, legal spirits and legal logics to analyze, synthesize, evaluate and reason the problems based on the concept of the rule of law to come to a conclusion and make a decision". From the perspective of phenomenology, Professor Chen Jinzhao argues that rule of law thinking is "the restricted expression of rule of law principles, legal concepts, legal principles, legal methods and legal technical provisions in thinking". Professor $\mathrm{Hu}$ Jianmiao believes that rule of law thinking is "the way of thinking that takes the legitimacy as the starting point and pursues fairness and justice according to legal logic and legal values" from the perspective of the values of rule of law. Rule of law thinking is developed on the basis of the concept and spirit of rule of law from all the perspectives. In essence, rule of law is the restriction of power. Cultivating leading cadres' rule of law thinking is to make leading cadres subject to the restriction of rule of law when they execute their power to not to go beyond the limitations of rule of law and regularize their behaviors of executing power. However, the traditional "official-oriented" thinking had deeply affected the way of thinking and behaviors of leading cadres. As the social convention of China, "official-oriented" thinking may affect people's choice subtly. As Max Weber says, "we will define convention as a unique and consistent action. It is repeated for that people get used to it due to pure imitation"[1]. The privilege idea and unequal awareness contained in "officialoriented" thinking is the greatest restriction of cultivating rule of law thinking, which is imitated and adapted by leading cadres. The role of long-term habit is great, and its impact on cultivating rule of law thinking of leading cadres cannot be changed overnight.

\section{B. Political-legal thinking is still the important factor restricting the formation of rule of law thinking of leading cadres}

It is generally believed that rule of law corresponds to rule of man. Thus, rule of law thinking should correspond to rule of man thinking. However, Professor Chen Jinzhao proposes on the basis of methodology analysis of rule of law thinking, "at present, political-legal thinking corresponds to rule of law thinking"[2] Political-legal thinking is developed throughout the history of long-term revolutionary practice of CPC. In the age of revolution, due to the needs of political struggle, CPC led people in revolution by policy. Long-term revolutionary struggle has strengthened the thinking. Political-legal thinking is still affecting the ruling party as well as the leading cadres of ruling party until today. Political-legal thinking focuses on politics and policies rather than law. It emphasizes maintaining political power. Power controls right, but rights do not restrict power. In fact, political-legal thinking embodies law instrumentalism. In political-legal thinking, political power is the master, and law has become the tool to maintain the political stability without any respect. It is contrary to rule of law thinking with focus on law. Rule of law thinking requires leading cadres to do something but not everything and administrate according to law within the scope of power. But leading cadres with political-legal thinking may go beyond power under the stimulation of political performance to abuse power and result in damage and catastrophe. In practice, the 
phenomenon of "being absolutely obedient to leaders and regarding law as the head lice of monk, rope of binding oneself, cage of restricting oneself and stumbling block to promotion" [3] is the realistic reflection of political-legal thinking. Leading cadres under the impact of political-legal thinking for a long time will easily develop thinking set, which is difficult to be eliminated.

\section{Quality of leading cadres is the key factor restricting the cultivation of rule of law thinking}

The core of rule of law is restriction of power. Rule of law is restriction in a certain sense for leading cadres. Cultivating rule of law thinking of leading cadres is to put the straightjacket on leading cadres so that leading cadres should exercise their power within the limitation of rule of law. However, people tend to go after gain and avoid harm. As Meyer put it, "selfish behavioral tendency plays a dominant role in genetic composition of our behaviors and psychology. In the previous ages of human beings, selfish behaviors were chosen by nature"[4]. Under the control of egoism, rule of law can restrict leading cadres and cultivate their rule of law thinking. The development and achievement of this proposition is a difficult thing. As in the situation of egoism, cultivating rule of law thinking of leading cadres can only depend on the quality of leading cadres, especially the degree of moral cultivation. The highly moral and self-disciplined leading cadres can accept rule of law thinking and wear the straightjacket more easily. However, the less moral and selfdisciplined leading cadres may accept rule of law thinking and wear the straightjacket less easily. Although the party places equal stress on integrity and ability when selecting cadres, not all the leading cadres have a high degree of moral standard from the recent anti-corrupt practice. Some leading cadres are corrupted to a serious degree. Generally, the quality of leading cadres is not high. In such a context, it is difficult to make leading cadres accept rule of law thinking and adopt rule of law thinking to think and solve problems.

\section{COUNTERMEASURES OF CULTIVATING RULE OF LAW THINKING OF LEADING CADRES}

\section{A. Construction of normal and institutional mechanism of rule of law education of leading cadres}

The American educational psychologist Jerome Bruner believes that human's cognitive process is to connect new information and psychological framework (or real model) acquired previously to actively constitute their knowledge. It can be said that human's cognitive process is the process of actively constituting new knowledge. But "thinking is the process that a person understands something by conceptual or typed activities". Thus, the primary task of education is to guide individuals to turn cognitive structure into new one, make individuals to feel the world by new cognitive way and cultivate new way of thinking. Rule of law education owns the same function. The rule of law education of leading cadres needs to change the way of thinking of leading cadres, change the original "official-oriented" thinking and political-legal thinking of leading cadres and cultivate their rule of law thinking gradually. Currently, strengthening rule of law education of leading cadres has reached a consensus. The author believes that we need to ensure the normal and institutional mechanism of rule of law education of leading cadres when strengthening their rule of law education. The party schools, schools of administration and schools of cadres should record the rule of law education of leading cadres and regard it as their annual assessment as well as the important basis for promotion to promote the institutional, special and long-term rule of law education of leading cadres so that the system will not be changed with the changes of leaders and their ideas and attention. After the system is developed, they should insist on it so that the cultivation of rule of law thinking of leading cadres will be effective.

\section{B. Stimulate the internal motivation of cultivation of rule of law thinking of leading cadres}

In order to make leading cadres accept the restriction of rule of law and apply rule of law thinking to administrate, we need to improve the quality of leading cadres, especially the moral quality. In addition, we should start from the perspective of behaviorism to stimulate the internal motivation of cultivating the rule of law thinking of leading cadres so that they can realize that cultivation of rule of law thinking is favorable. According to the reinforcement theory of the American behaviorism psychologist Skinner, he argues that people or animals will take action to affect the environment for a kind of purpose. When the outcomes of the behavior are favorable, the behavior will appear repeatedly. When the outcomes are unfavorable, the behavior will be weakened or disappear. According to the reinforcement theory, the leading cadres should realize that rule of law thinking is favorable for individuals for repeated application of rule of law thinking. Otherwise, the behavior will not appear repeatedly or turn into a habit. However, how does the feature that rule of law thinking restricts exercising power by leading cadres make them think rule of law thinking favorable? The author thinks that we can try from the following two aspects. First of all, we need to guide leading cadres to establish correct view of power. View of power is people's overall view of power, including the cognition and attitude of source of power, purpose and way of exercising power. Leading cadres should own the correct view of power of "power from and for people, benefit for people and concern for people". Once the leading cadres really understand the connotation of view of power, they will realize that rule of law thinking is not only the restriction of themselves but also the protection of themselves. With the protection of rule of law thinking, they can resist the temptation of money and beauty effectively and benefit themselves. Second, create a good atmosphere that leading cadres make use of rule of law thinking. During the selection and appointment of leading cadres, rule of law standards should be included in the standards of selection and appointment and select those who are good at applying rule of law thinking and way to develop the demonstration effect. Thus, the leading cadres can obtain the benefit by applying rule of law thinking and administrating by law. Only in this way can make more leading cadres actively cultivate rule of law thinking and develop the virtuous cycle of cultivation of rule of law thinking of leading cadres. 
C. Strengthen the awareness of civil rights and develop rule of law thinking of leading cadres

Market economy emphasizes equality, freedom, fairness and efficiency, stimulates people's subjectivity to a maximum degree, make people focus more on their own rights and safeguard their legitimate rights and interests. It can be said that the process of establishing system of market economy is the process of strengthening people's consciousness of right. In the future, with the overall establishment of socialist market economic system of China, people's consciousness of right will be strengthened constantly. In this context, strengthening people's consciousness of right will affect the cultivation of rule of law thinking of leading cadres and make them regard cultivation of rule of law thinking as a compulsory course. If leading cadres cannot covert their way of thinking timely or apply rule of law thinking to reply to the appeal of rights of people but follow the old way of thinking, they will affect the effect of administration by law and social harmony and stability, trigger group incidents and aggravate social conflicts. Certainly, strengthening people's consciousness of right does not mean the generalization of civil rights. Civil rights should be restricted by constitution and law rather than random creation of new rights. Otherwise, it may result in social conflicts rather than power restricted by rights. "Generalization of right" brought by sloppy right setting boosts the conflict in a general sense and from the standard level. It will result in the paradox of "more legislation and less order"[5]. Besides, it will result in conflicts in object and effect of right setting, classified protection of rights, country and society and right and morality. Strengthening the awareness of civil rights is to make people actively and correctly claim the rights to make leading cadres to walk on the road of rule of law, apply rule of law thinking to administrate by law, solve conflicts by law and solve disputes to develop the greatest social value consensus.

\section{CONCLUSION}

The formation of the rule of law thinking of leading cadres is subject to various constraints. It is destined to take a long time to eliminate the negative impact of these constraints. In order to solve the problem, we must take active measures, such as construction of normal and institutional mechanism of rule of law education of leading cadres; stimulate the internal motivation of cultivation of rule of law thinking of leading cadres and strengthen the awareness of civil rights and develop rule of law thinking of leading cadres.

\section{REFERENCES}

[1] Max Weber, Economics, Social Fields and Power, Joint Publishing, 1998, p.14

[2] Chen Jinzhao, 'Interpretation of thinking and way of rule of law', Journal of National Prosecutors College, 2013, No. 2.

[3] Gu Hequan, 'Current Status and Countermeasures of Rule of Law Thinking of Grassroot Cadres', The Journal of CPC Yunnan Provincial Committee School, 2013, No. 2

[4] Cited from Zheng Yefu, Trust, CITIC Press Group, 2015, p.26.

[5] Chen Linlin, 'Reflection on Generalization of Rights in the Process of Rule of Law in China', Chinese Journal of Law, 2014, No. 1. 